\title{
Infrapubic Approach for Malleable Penile Implant
}

\author{
Oswaldo L. D. Berg
}

Sexual Medicine Clinic, Department of Urology, Hospital da Lagoa, Rio de Janeiro, Brazil

\begin{abstract}
Purpose: Today, we find that the implant of malleable prostheses still plays a leading role in the surgical treatment of erectile dysfunction. These may involve patients for which the cosmetic advantages of inflatable devices are not as important as low cost, the easier use and less incidence of mechanical complications in the malleable implants. This paper demonstrates infrapubic approach as a technical option for this kind of implant.

Surgical Technique: It offers technical resources and emphasizes the facility in using the method, reducing cutaneous exposure, which diminishes risks of contamination.

Comments: As occurs in inflatable implants, when implanting malleable prostheses through the infrapubic access, care must also be taken regarding the possibility of lesion to the vascular-nervous bundle. On the other hand, the approach through the dorsal surface of the corpora cavernosa has a natural capacity for anatomical protection of the urethra, not requiring transurethral catheterization. This benefit is of the utmost importance when considering possible causes of per and postoperative morbidity.

Accordingly, we can consider that the infrapubic approach is an effective method and prevails as a technical option for implanting malleable prostheses.
\end{abstract}

Key words: erectile dysfunction; penile prosthesis; urologic surgical procedures, male

Int Braz J Urol. 2011; 37: 94-9

\section{INTRODUCTION}

Since 1936 when Nikolaj Bogaraz reconstructed an amputated penis using a tubular abdominal graft in which he inserted a section of rib cartilage, the search for ideal materials and techniques for penile implants has been continuous. Over the years, acrylic, polyethylene, silastic, silicon rubber and other prostheses have been used, whether for rigid, articulated, malleable and later inflatable of one, two or three-piece constitution $(1,2)$.

Currently, malleable prostheses available in the market are quite similar to each other, with a central structure consisting of steel or silver filaments covered by two or more layers of silicon sheath. They all offer various modalities of size adjustment, by cutting or adding extensors to their proximal portion.

Although today patients and surgeons prefer inflatable prostheses, some circumstances may require the malleable implant. These may involve patients for which the cosmetic advantages of inflatable devices are not as important as low cost, the easier use and less incidence of mechanical complications in the malleable implants (1-6).

With regard to the surgical technique, various approaches have been described for implanting penile prostheses: the dorsal subcoronal, penile proximal, longitudinal penoscrotal, transverse penoscrotal perineal and combined incisions (7). More recently, a minimally invasive infrapubic approach was proposed 


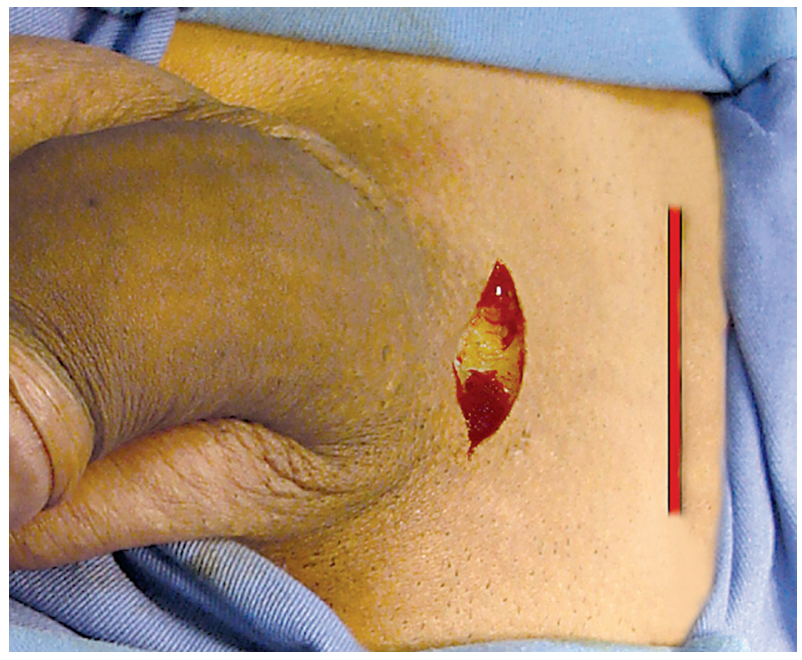

Figure 1 -Suggested incision. The red line sets the relation with the infrapubic incision proposed in the minimally invasive technique described for the three-piece inflatable implants.

for the implant of a three-piece inflatable prosthesis (8). The name used comes from the fact of making a single transverse incision below the pubis. The pur-

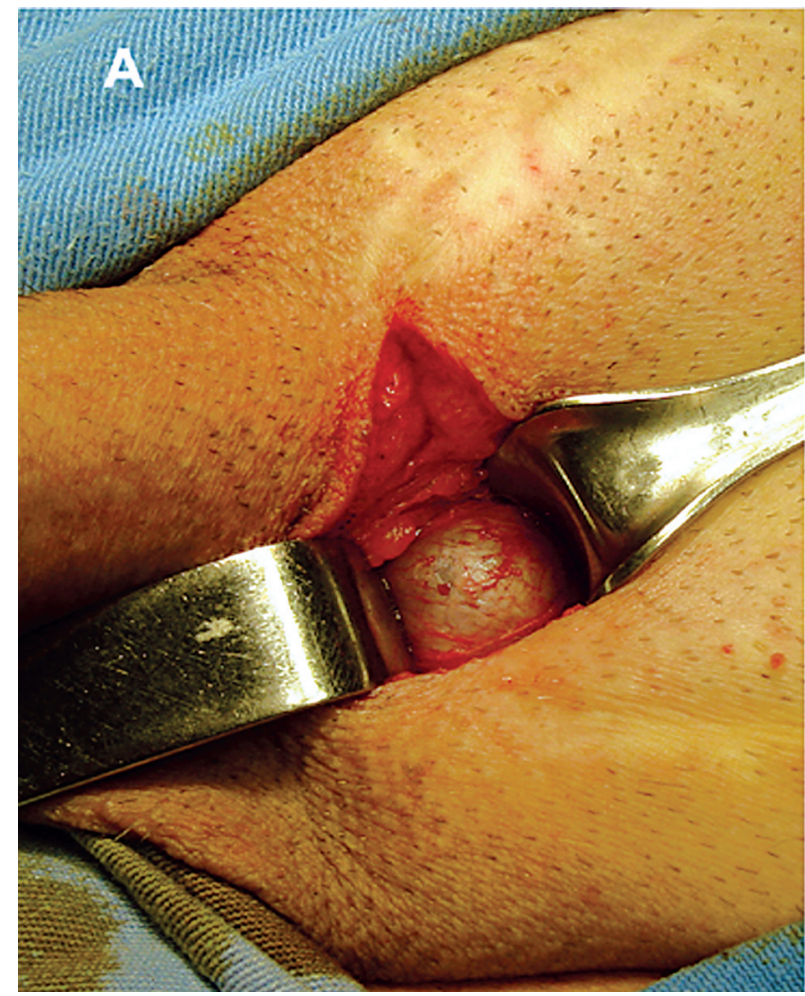

Figure 2-Identification and incision of the corpus cavernous. pose of this paper is to demonstrate the ease of this approach for the implant of malleable prostheses.

\section{SURGICAL TECHNIQUE}

The infrapubic approach adopted in our hospital is characterized by a two to three centimeter transverse incision, approximately one centimeter from the base of the penis (Figure-1).

Skin and subcutaneous tissue are incised using a conventional scalpel. Of course, care must be taken to prevent lesions both to the suspensory ligament of the penis and to the medial neurovascular bundle. With this in mind, the dissection is deepened using scissors, staying at each angle of the incision and thus keeping away from its center.

The corpora cavernosa are easily visible by a simple thrust of the penile axis. This procedure causes stretching and shrinkage of the corpora cavernosa, facilitating its identification and subsequent dissection (Figure-2A).

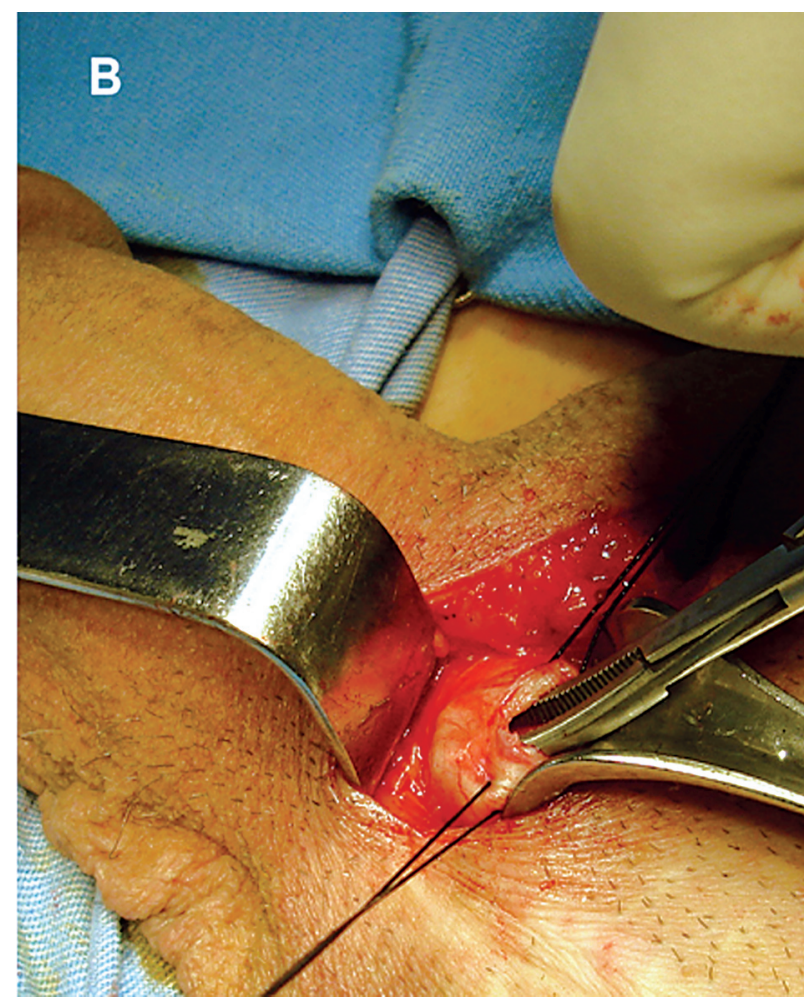




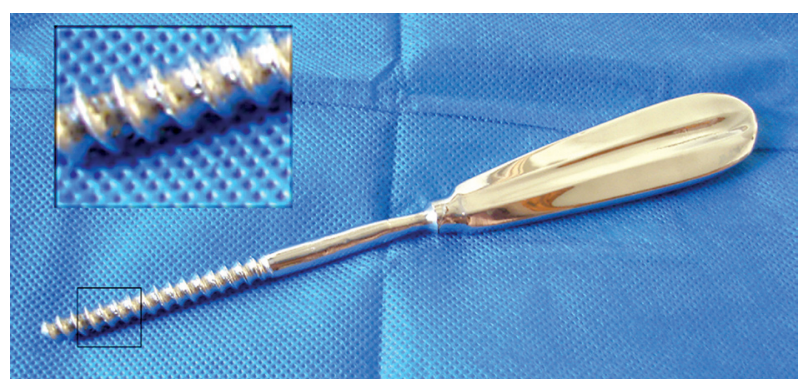

Figure 3-Cavernotome.

A small longitudinal incision on the dorsal surface of the corpus cavernous is made using a conventional scalpel between stay sutures. The erectile tissue is pushed down using Halsted forceps and the incision is extended to its two angles (Figure-2B).

The progressive dilation of the corpus cavernous is made using Heggar dilators in the proximal and distal directions, as described for the other approaches.
In cases where any adherences or fibrosis of the cavernous tissue hamper the dilation of the corpora cavernosa, several technical resources have been proposed (9-11). In such cases, in our Hospital, this dilation is mostly done by using a cavernotome developed by the urological unit. This instrument is characterized by a grip with a distal cylindrical end containing cutting spiral grooves (Figure-3). The grooved surface is considerably more effective than that of the dilators and file used previously. Its use consists of small delicate rotational and longitudinal movements in order to remove the portion of the cavernous tissue with fibrosis, pushing the rest down. It should be mentioned that the purpose is to "file" and not "pull out" the tissue. Extreme care must be taken when using the instrument, especially at the start of apprenticeship.

We used the following procedure to adapt the size of the prosthesis: first, it is introduced inverted in the proximal direction. Next, the maximum extension of the penis will determine the size of the
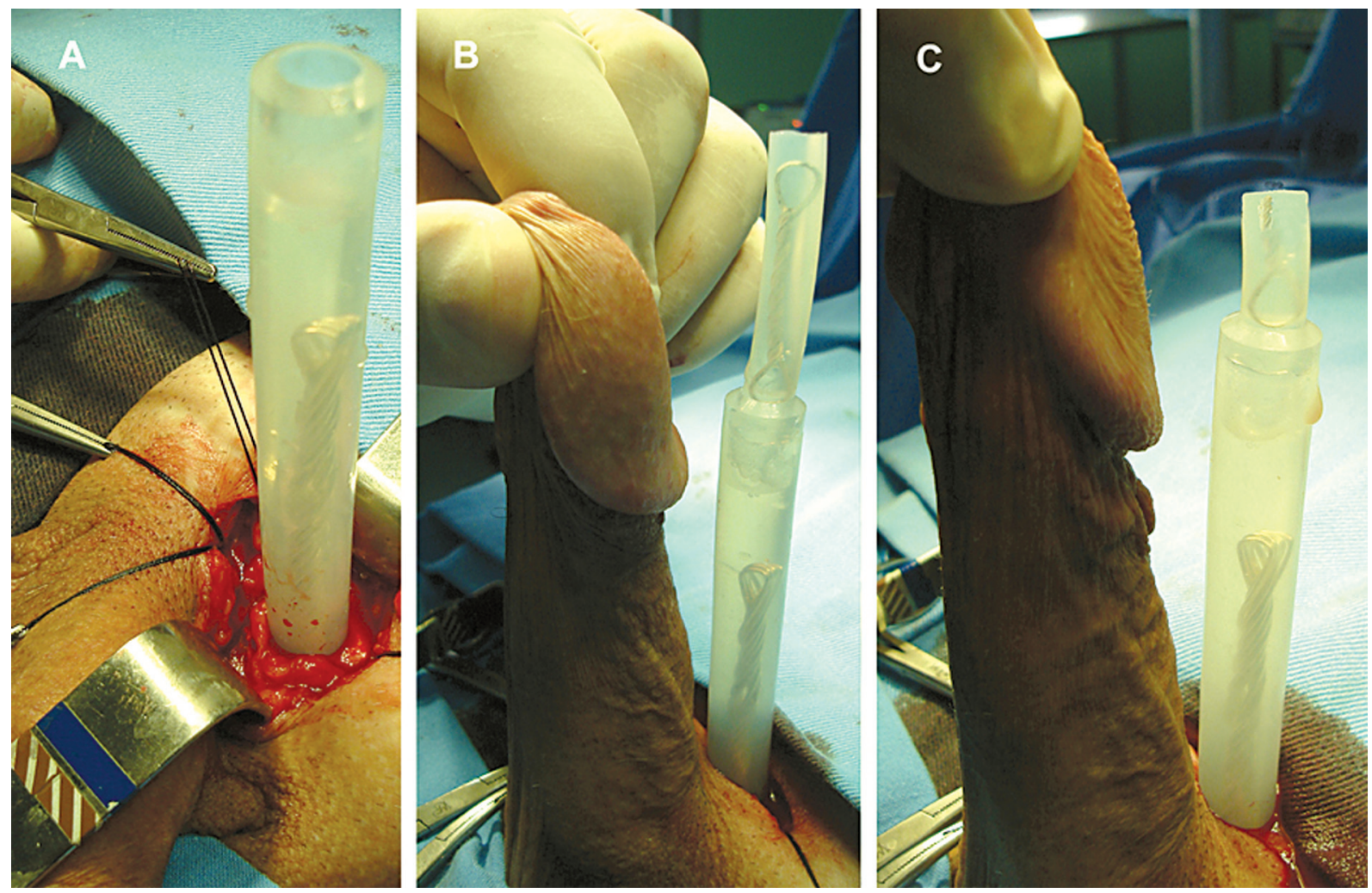

Figure 4-Procedure to adapt the size of the prosthesis. 

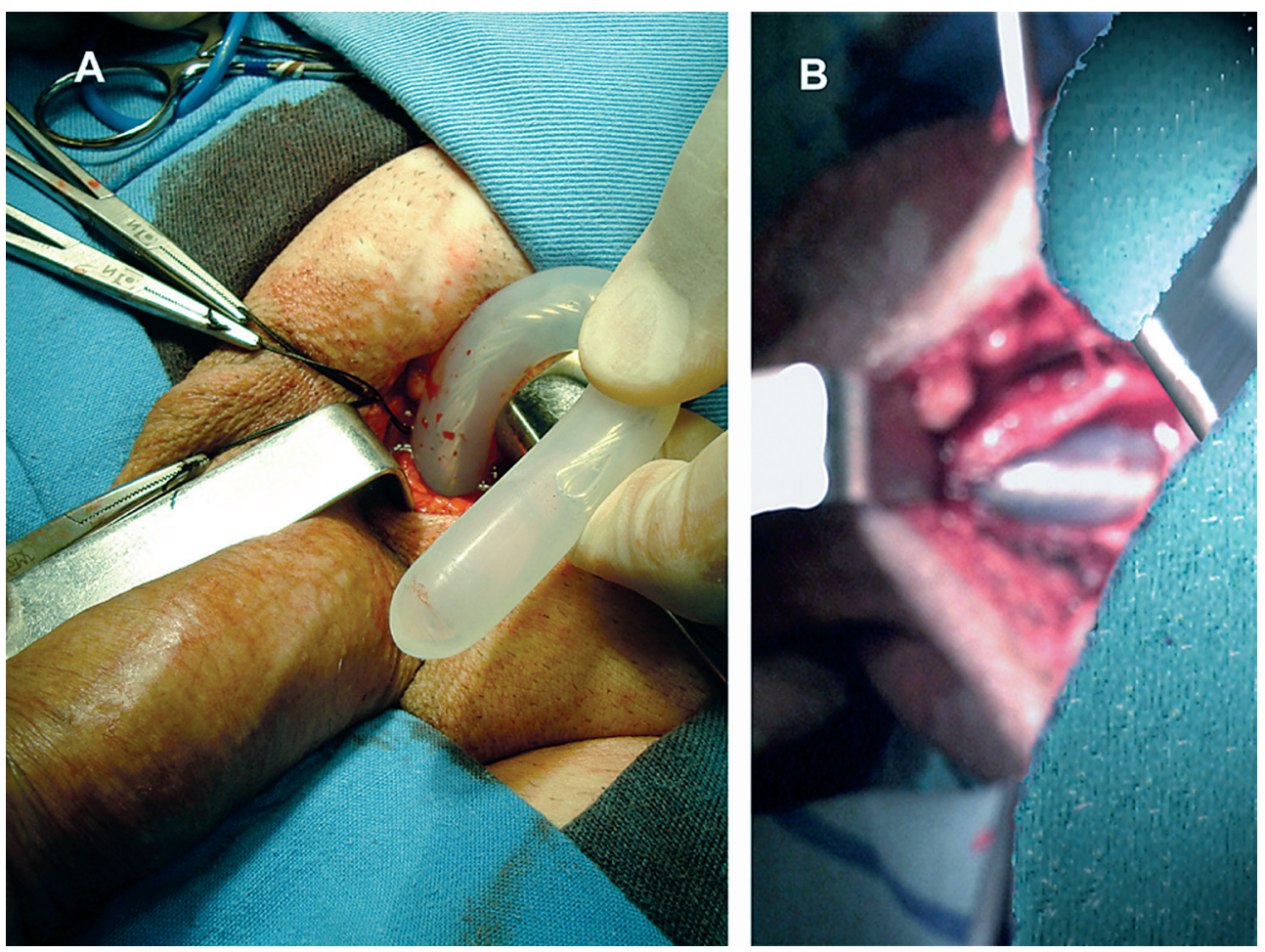

Figure 5 - Prosthesis position.

prosthesis. The section of the cylinder or adaptation with extensors is done by taking as reference the height corresponding to half the glans. The cylinder is then removed and replaced in its normal position. In our experience with this measuring method, when the prosthesis is introduced into its final position, the natural angulation of the corpus cavernous, at the base of the penis, adjusts perfectly to the prosthesis without requiring further corrections (Figure-4).

Before finally inserting the prosthesis, the entire process described herein above is repeated on the contralateral side.

This approach also involves the well-known resource of the loop curvature of the cylinder that especially facilitates its distal insertion and prevents deformities caused by angulations resulting from nudging the metal filament (Figure-5).

The synthesis of tunica albuginea is accomplished with a 3-0 continuous absorbable synthetic suture. Hemostasis is reviewed using diathermocoagulation and the other incision planes are closed with a 3-0 absorbable synthetic suture. Skin incision is closed in a continuous or subcuticular 5-0 absorb- able synthetic suture, in order to prevent the patient's discomfort when removing the suture (Figure-6A).

We only use an occlusive sterile surgical paper tape, since the careful review of hemostasia does not require larger compressive dressings that are, in fact, in this approach, of very little help (Figure-6B).

The proposed approach is being adopted in both primary surgery and reoperations. In such cases, it is fully in accordance with the basic principles of surgical interventions that recommend that the approach adopted in a region already previously manipulated is, whenever possible, through a fibrosis-free area. Accordingly, in the cases of revisions or reimplants of malleable prostheses, where the first operation was done through a penoscrotal approach, we consider the infrapubic approach to be first option in another intervention.

\section{COMMENTS}

The proposed approach as a technical option for the implant of malleable prostheses finds sup- 

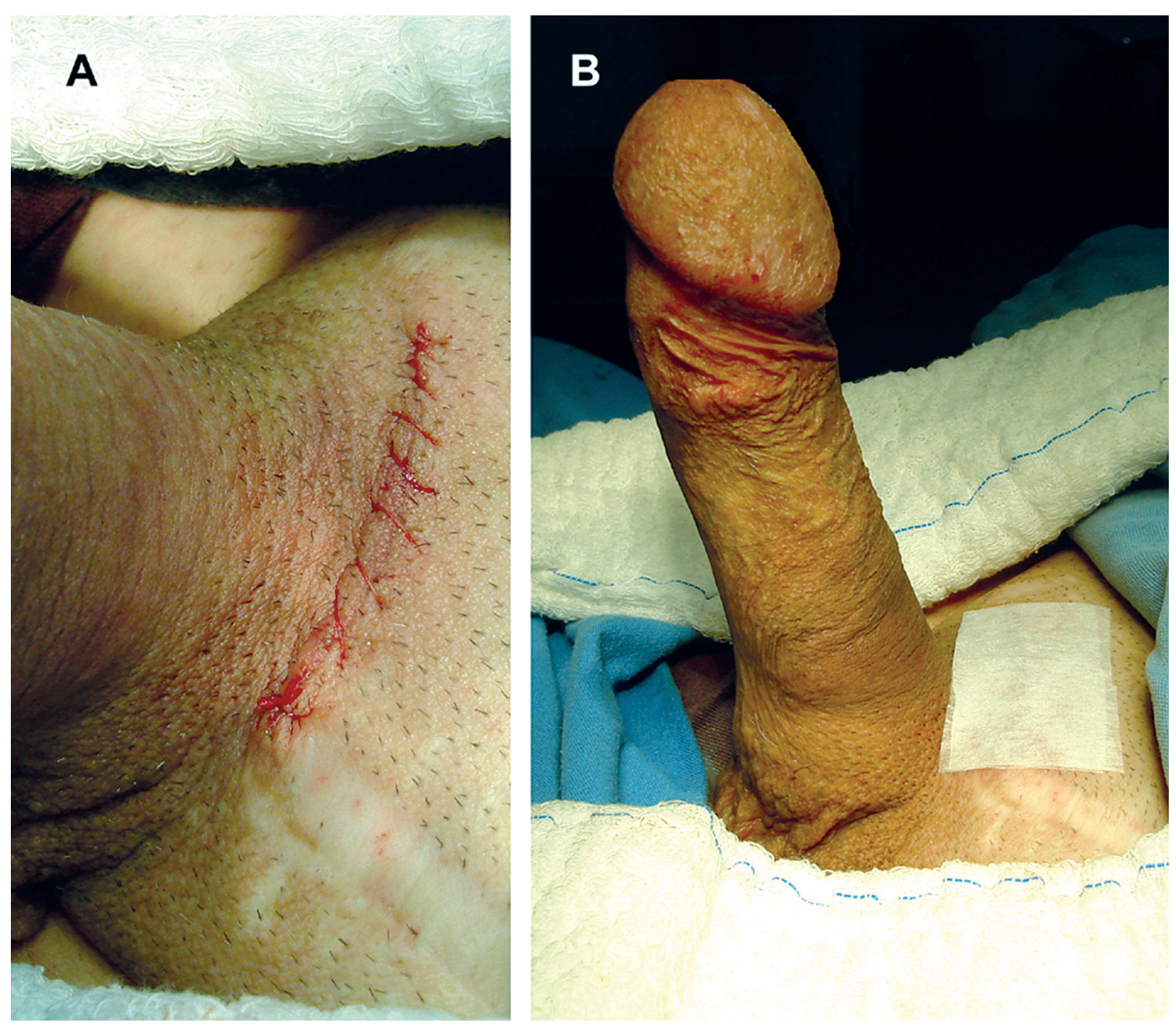

Figure 6 - Final aspect.

port when we consider that despite the advances in the technology of inflatable implants, the malleable prostheses are still used. This fact is due not only to the technical facility of its implantation and less risk of mechanical failure, but also mainly due to the much lower surgical cost (1-6).

The infrapubic approach has therefore been adopted in our hospital since 2007, also as a technical option for malleable penile implants. Considering how simple this approach is, it has practically totally substituted the longitudinal penoscrotal approach that we previously used.

Taking the three-piece inflatable prostheses as reference, today the penoscrotal approach is being widely used by surgeons, tending to substitute the infrapubic incision used previously in such procedures $(2,12)$. However, in recent years, a minimally invasive technique retrieves the infrapubic approach as an option for the three-piece inflatable implants (8).
Similarly, with regard to malleable prostheses, although a kind of infrapubic approach has been mentioned since 1976 by Kelâmi, we can state that, at present, this type of access is seldom addressed in medical literature, while the penoscrotal approach is more often mentioned by the surgeons $(1,2,7)$. Nevertheless, the infrapubic approach is also an excellent technical option in these cases (13-16).

When implanting the inflatable prostheses, the main benefit of the infrapubic approach is the possibility of direct vision for implanting the liquid reservoir. Its disadvantages include limited corpus cavernous exposure and difficulty in anchoring the pump in the scrotum. Although lesions of the dorsal nerves of the penis seldom occur during this procedure, it is a risk to be considered in the dissection to expose the corpora cavernosa. The benefits of the penoscrotal approach include better exposure of the corpus cavernous, impossibility of damaging dorsal 
nerves of the penis and more facility in anchoring the inflating pump. Its main disadvantages are more possibility of urethral lesion and blindly implant of the reservoir in the retropubic space (17).

As occurs in inflatable implants, when implanting malleable prostheses through the infrapubic access care must also be taken regarding the possibility of lesion to the vascular-nervous bundle. On the other hand, the approach through the dorsal surface of the corpora cavernosa has a natural capacity for anatomical protection of the urethra, not requiring transurethral catheterism. This benefit is of the utmost importance when considering possible causes of per and postoperative morbidity (18).

Accordingly, we can consider that the infrapubic approach is an effective method and prevails as a technical option for implanting malleable prostheses.

For obvious reasons, the benefits and disadvantages must be carefully considered in obese patients with extensive adipose panicle in the region to be cut.

\section{CONFLICT OF INTEREST}

None declared.

\section{REFERENCES}

1. Henry GD: Historical review of penile prosthesis design and surgical techniques: part 1 of a three-part review series on penile prosthetic surgery. J Sex Med. 2009; 6: 675-81.

2. Sadeghi-Nejad H: Penile prosthesis surgery: a review of prosthetic devices and associated complications. J Sex Med. 2007; 4: 296-309. Erratum in: J Sex Med. 2007; 4: 1520.

3. Wilson SK, Delk JR, Salem EA, Cleves MA: Longterm survival of inflatable penile prostheses: single surgical group experience with 2,384 first-time implants spanning two decades. J Sex Med. 2007; 4: 1074-9.

4. Lotan Y, Roehrborn CG, McConnell JD, Hendin BN: Factors influencing the outcomes of penile prosthesis surgery at a teaching institution. Urology. 2003; 62: 918-21.

5. Dorflinger T, Bruskewitz R: AMS malleable penile prosthesis. Urology. 1986; 28: 480-5.

6. Choi HK, Cho IR, Xin ZC: Ten years of experience with various penile prosthesis in Korean. Yonsei Med J. 1994; 35: 209-17.
7. Glina S, Martins F: Técnicas de implante. In: Disfunção Sexual Masculina. São Paulo, Inst H Hellis.2002; pp. 259-62.

8. Perito PE: Minimally invasive infrapubic inflatable penile implant. J Sex Med. 2008; 5: 27-30.

9. Montague DK, Angermeier KW: Corporeal excavation: new technique for penile prosthesis implantation in men with severe corporeal fibrosis. Urology. 2006; 67: 1072-5.

10. Shaeer O, Shaeer A: Corporoscopic excavation of the fibrosed corpora cavernosa for penile prosethesis implantation: optical corporotomy and trans-corporeal resection, Shaeer's technique. J Sex Med. 2007; 4: 218-25.

11. Shaeer O: Implantation of penile prosthesis in cases of corporeal fibrosis: modified Shaeer's excavation technique. J Sex Med. 2008; 5: 2470-6.

12. Candela JV, Hellstrom WJ: Three-piece inflatable penile prosthesis implantation: a comparison of the penoscrotal and infrapubic surgical approaches. J La State Med Soc. 1996; 148: 296-301.

13. Kelâmi A: "Infrapubic" approach for small-carrion prosthesis in erectile impotence. Urology. 1976; 8: 164.

14. Kelâmi A: Implantation of Small-Carrion prosthesis in the treatment of erectile impotence after priapism: difficulties and effects. Urol Int. 1985; 40: 343-6.

15. Kelâmi A: Erictile impotence, small-carrion prosthesis and the 'infrapubic' approach. Eur Urol. 1977; 3: 299-302.

16. Berg O, Leite A: Comparative study penoscrotal and infrapubic access routes for implanting malleable penile prostheses. J Sex Med. 2010: 7(Suppl 2): 51-68.

17. Montague DK, Angermeir KW: Surgical approaches for penile prosthesis implantation: penoscrotal vs infrapubic. Int J Impot Res. 2003; 15(Suppl 5): S134-5.

18. Anafarta K, Safak M, Bedük Y, Baltaci S, Aydos K: Clinical experience with inflatable and malleable penile implants in 104 patients. Urol Int. 1996; 56: 100-4.

\section{Accepted after revision:}

July 5, 2010

\section{Correspondence address:}

Dr. Oswaldo Luiz Dias Berg

Rua São Clemente, 114 / 708

Rio de Janeiro, RJ, 22160-000, Brazil

Fax: + 5521 2235-2828

E-mail: berg@vetor.com.br 